\title{
Methicillin-resistant Staphylococcus aureus in North-east Croatia
}

\author{
Tajana Pastuović ${ }^{1}$, Magdalena Perić $^{1 *}$, Zinka Bošnjak ${ }^{1}$, Nataša Ružman ${ }^{1}$, \\ Patricia Reisz Majić ${ }^{2}$, Jasminka Talapko ${ }^{3}$, Vlasta Atalić ${ }^{1}$, Snježana Loci-Zvocak ${ }^{1}$, \\ Dubravka Vuković ${ }^{1}$
}

${ }^{1}$ Institute of Public Health for the Osijek-Baranja County, Osijek, Croatia ${ }^{2}$ University Hospital Osijek, Osijek Croatia, ${ }^{3}$ Faculty of Medicine, Osijek Croatia

\footnotetext{
${ }^{*}$ Corresponding author: magdalena0706@gmail.com Tel.: + 38531225725

Fax: + 38531206807
}

Received: 20 February 2015

Accepted: 8 May 2015

Key words: Staphylococcus aureus • MRSA $\cdot$ Healthcare-associated infection
Objective. The aim of this 5-year study was to determine the frequency and antibiotic susceptibility of methicillin-resistant Staphylococcus aureus (MRSA)-related infections at Osijek Clinical Hospital. Materials and methods. A total of 1987 staphylococci-infected clinical isolates were collected and analysed at the Microbiology Department of the Public Health Institute of Osijek-Baranja County. Results. Between 2008 and 2012, the average rate of MRSA-related infections in staphylococci-infected patients was $27.4 \%$. The proportion of MRSArelated infections on all Staphylococcus aureus (S. aureus) isolates from clinical specimens showed a decreasing trend, from $32.6 \%$ in 2008 to $25.5 \%$ in 2012 . MRSA-related infections were mostly detected in wound swabs $(50.6 \%)$ and aspirates $(28.8 \%)$ of patients hospitalized in the surgical (49.8\%) and intensive care units (27.9\%). MRSA-related infection showed an increase compared to $S$. aureus-infections in samples of wounds and aspirates in 2011 and 2012 (57.9\%/34.9\% and $35.2 \% / 16.3 \%$, respectively). The majority of strains of MRSA-related infections were resistant to several antibiotics, including erythromycin and clindamycin, where susceptibility were less than $10 \%$. All MRSA isolates were susceptible to vancomycin, teicoplanin and linezolid. Therefore, antibiotic therapies for MRSA infections include vancomycin, teicoplanin and linezolid, but microbiological diagnostics need to be performed in order to know when the use of glycopeptides and oxazolidinones is indicated. Conclusion. Our results suggest that appropriate prevention measures, combined with the more rational use of antibiotics are crucial to reduce the spread of MRSA-related infection in healthcare settings. Further monitoring is necessary of the incidence and antibiotic susceptibility of MRSA-related infections in our community.

\section{Introduction}

The bacterium Staphylococcus aureus ( $S$. aureus) is a serious opportunistic human pathogen (1). It belongs to normal bacterial flora and is often detected in the nasal vestibule and on other body surfaces in 20\%-30\% of humans. S. aureus synthesizes more than 30 virulence factors that may cause numerous clinical symptoms. In addition to local skin infection, a typical sign of a staphylococcal infection, it also leads to abscesses, osteomyelitis, pneumonia, sepsis, endocarditis, and post-operative infections. More- 
over, $S$. aureus toxins may result in poisoning and toxic shock $(2,3)$.

The remarkable ability of $S$. aureus to develop antibiotic resistance makes it a worldwide problem. Through the process of natural selection (mostly transmission), methicillin-resistant $S$. aureus (MRSA) has developed resistance to macrolides, linkosamides and aminoglycosides and an entire class of antibiotics called beta-lactams (including the penicillins and the cephalosporins). Staphylococcal strains that are susceptible to these antibiotics are classified as methicillinsensitive $S$. aureus (MSSA). The first MRSA was isolated in Great Britain in 1961, then in the USA in 1968, which was followed by its detection in Japan, Europe and Australia. MRSA has been one of the most common causes of healthcare-associated infections. It has been estimated that MRSA infects 171,200 people in the EU, Island and Norway annually, leading to $44 \%$ of all cases of health-care associated infections (4-7). The frequency of MRSA-related infections has slowed down in the West, but in the Northeast, Midwest and South of the USA MRSArelated infections have shown an increase. $S$. aureus-related infections have been shown to be increasing in the Northeast, Midwest, South and in the West (8).

There are two types of MRSA infections in human hosts: hospital-acquired MRSA (HA-MRSA) and community acquired MRSA (CA-MRSA), and there is one type of MRSA infection in livestock: livestockassociated MRSA (LA-MRSA). HA-MRSA is a secondary infection, which patients pick up in hospital. CA-MRSA infection is an infection which develops outside the hospital, through exposure to a carrier or contaminated surface in the wider community. LA-MRSA infections colonize livestock, including pigs, cattle and poultry $(6,9,10)$. Some studies have suggested that previous hospitalization is associated with CA-MRSA $(8,11)$.
MRSA spreads easily in hospitals, usually through the hands of health workers or contaminated objects. The colonization of health workers with MRSA is especially dangerous. Risk factors that contribute to MRSA spread are subtherapeutic doses or the overuse of antibiotics, long-term hospital stay and intravascular catheterizations in intensive care units (ICUs). The potential sites for MRSA infection in hospital patients are open wounds, intravenous catheters and the respiratory and urinary tracts $(4,12-14)$.

MRSA infections in hospital settings have been a serious issue across the world. MRSA infections prolong hospital stay and excessive antibiotic usage which raise the total cost of hospitalization. Hand hygiene, decontamination, and contact isolation of colonized and infected patients are the most important prevention measures. MRSA strains can be detected in clinical specimens using standard microbiological procedures, following the guidelines set by the $2011 \mathrm{Eu}-$ ropean Committee on Antimicrobial Sensitivity Testing (EUCAST). MRSA is a multidrug resistant isolate, causing infections that are difficult to treat. In treatment of MRSArelated infection vancomycin, linezolid and tigecyclin (15-17) may be used.

To our knowledge, this is the first study on MRSA-related infection frequency and antibiotic resistance in hospital patients from north-east Croatia. This was a 5-year study that analysed 1987 staphylococci-infected clinical specimens collected at Osijek Clinical Hospital.

\section{Materials and methods}

\section{Samples}

This study was performed between January 2008 and December 2012, and included 1987 staphylococci-infected isolates. All isolates were collected at the Osijek Clinical Hospital Centre. The presence of Staphylococcus 
was analysed in clinical samples: aspirates, catheters, wounds, blood, liquor and urine, which are collected on the surgical, internal medicine, paediatric, infectious diseases and ICU wards. All samples were analysed at the Microbiology Department of the Institute of Public Health of the Osijek-Baranja County. Only one sample per patient was included in the study.

\section{Laboratory methods}

Samples were cultivated on blood agar plates and incubated at $37^{\circ} \mathrm{C}$ for $18-24$ hours in a microbiology laboratory. The presence of Staphylococcus was confirmed by the microscopic analysis of Gram-stained samples and a catalase test. In order to distinguish between $S$. aureus and coagulase-negative staphylococci (CoNS) we used deoxyribonuclease (DNase), coagulase and latex agglutination tests (Bio-Rad, Latex agglutination test for the identification of Staphylococcus aureus, Version 2012.). MRSA was determined from its resistance to cefoxitin by the disk diffusion technique. Cefoxitin resistant MRSA was confirmed by a fast latex agglutination test that detects penicillin-bound proteins (Oxoid, Test kit for the detection of PBP 2', Version 2012.). MRSA isolates that were $\mathrm{PBP} 2{ }^{\prime}$ agglutination-negative were further verified by an automatic identification system VITEK (BioMérieux, Vitek 2, Version 2008.).

The antibiotic susceptibility of MRSA was analysed to the following antimicrobial drugs: ciprofloxacin $(5 \mu \mathrm{g})$, gentamycin (10 $\mu \mathrm{g})$, clindamycin $(2 \mu \mathrm{g})$, erythromycin $(15$ $\mu \mathrm{g})$, netilmycin $(10 \mu \mathrm{g})$, linezolid $(10 \mu \mathrm{g})$, rifampicin $(5 \mu \mathrm{g})$, teicoplanin $(30 \mu \mathrm{g})$, vancomycin $(5 \mu \mathrm{g})$ and sulfamethoxazoletrimethoprim $(1.25 / 23.75 \mu \mathrm{g})$. EUCAST guidelines were followed for the susceptibility and result analysis.

Methicillin resistance was evaluated by a cefoxitin disk diffusion test. Müller-Hinton agar was covered with a bacterial suspension to the density of the McFarland 0.5 standard and incubated for $18-24$ hours in air at $37^{\circ} \mathrm{C}$. A bacterial isolate was considered to be resistant to all beta-lactam antibiotics if the size of its inhibition zone was $<22 \mathrm{~mm}$. For the strains with border values for inhibition zones diameters for cefoxitin the minimal inhibitory concentration (MIC) was determined. Isolates with values $>4 \mathrm{mg} / \mathrm{l}$ were considered to be MRSA-positive $(15,18,19)$.

\section{Ethics statement}

This study was approved by the Ethics Committee of the Institute of Public Health of the Osijek-Baranja County and performed according to the ethical principles of the Helsinki declarations.

\section{Statistical analysis}

The $\chi^{2}$ and Fisher's exact test, as appropriate, were used to compare percentage data (i.e., distribution between $S$. aureus-related infections and MRSA-related infections in different hospital units by years; distribution between $S$. aureus-related infections and MRSA-related infections in different clinical samples). Odds ratios (ORs) with 95\% confidence intervals (CIs) were calculated to show the strength and direction of associations. For all tests, p values $<0.05$ were considered statistically significant. Statistical analyses were performed using Statistica 8.0 (StatSoft) and Microsoft Office Excel 2007/2010 (Microsoft).

\section{Results}

The number of $S$. aureus-related infections and MRSA-related infections from aspirates, wounds, catheters, blood, urine and liquor samples collected at the Osijek Clinical Hospital Centre between 2008 and 2012 is presented in Table 1. 
Table 1 Proportion of S. aureus-related infections and MRSA-related infections in different clinical samples per year

\begin{tabular}{|c|c|c|c|c|c|c|c|c|}
\hline \multirow{3}{*}{ Year } & \multirow{3}{*}{ Infection } & \multicolumn{6}{|c|}{ Different clinical samples } & \multirow{3}{*}{ Total } \\
\hline & & Aspirates & Wounds & Catheters & Blood & Urine & Liquor & \\
\hline & & n (\%) & n (\%) & $\mathrm{n}(\%)$ & n (\%) & $\mathrm{n}(\%)$ & n (\%) & \\
\hline \multirow{2}{*}{2008} & S. aureus & $54(21.7)$ & $108(43.4)$ & $14(5.6)$ & $46(18.5)$ & $19(7.6)$ & $8(3.2)$ & 249 \\
\hline & MRSA & $32(26.6)$ & $67(55.8)$ & $3(2.5)$ & $11(9.3)$ & $4(3.3)$ & $3(2.5)$ & 120 \\
\hline \multirow{2}{*}{2009} & S. aureus & $76(24)$ & $118(37.3)$ & $34(10.8)$ & $63(19.9)$ & $14(4.5)$ & $11(3.5)$ & 316 \\
\hline & MRSA & $38(28.1)$ & $67(49.6)$ & $3(2.2)$ & $16(11.9)$ & $2(1.5)$ & $9(6.7)$ & 135 \\
\hline \multirow{2}{*}{2010} & S. aureus & $69(20.8)$ & $123(37.2)$ & $39(11.8)$ & $72(21.8)$ & $9(2.7)$ & $19(5.7)$ & 331 \\
\hline & MRSA & $29(29.9)$ & $49(50.5)$ & $3(3.1)$ & $6(6.2)$ & $1(1)$ & $9(9.3)$ & 97 \\
\hline \multirow{2}{*}{2011} & S. aureus & $59(20.2)$ & $102(34.9)$ & $33(11.3)$ & $67(22.9)$ & $13(4.5)$ & $18(6.2)$ & 292 \\
\hline & MRSA & $26(25.5)$ & $59(57.9)$ & $1(0.9)$ & $8(7.9)$ & $3(2.9)$ & $5(4.9)$ & 102 \\
\hline \multirow{2}{*}{2012} & S. aureus & $42(16.3)$ & $98(38.1)$ & $29(11.3)$ & $56(21.8)$ & $20(7.8)$ & $12(4.7)$ & 257 \\
\hline & MRSA & $31(35.2)$ & $32(36.4)$ & $4(4.5)$ & $13(14.8)$ & $6(6.8)$ & $2(2.3)$ & 88 \\
\hline
\end{tabular}

S. aureus=Staphylococcus aureus; MRSA=methicillin-resistant Staphylococcus aureus.

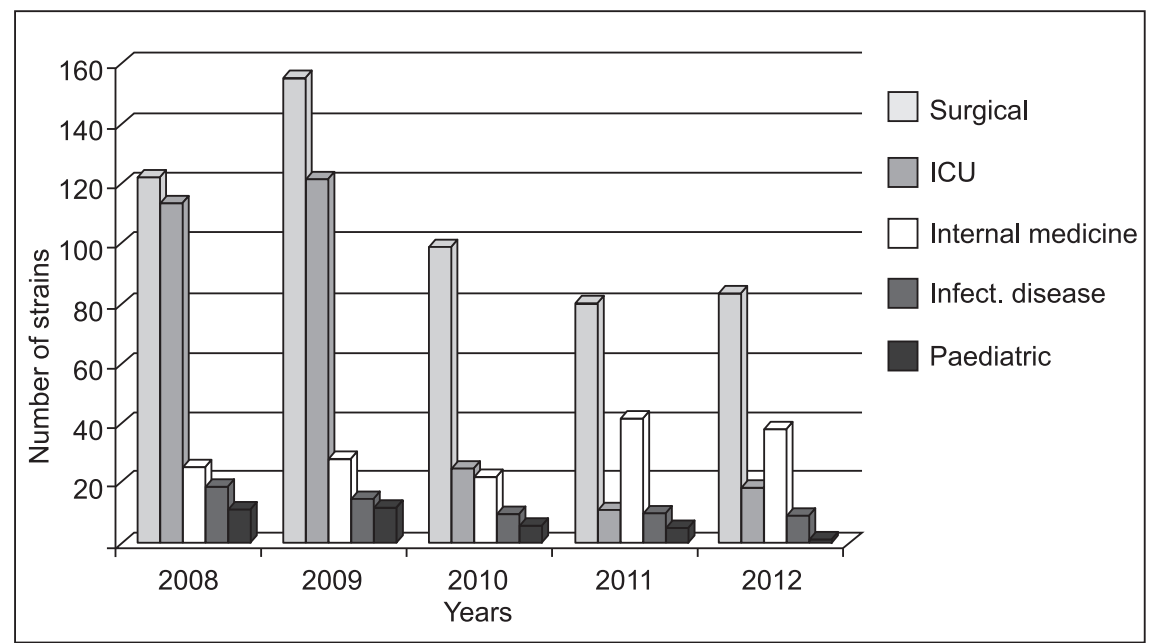

Figure 1 MRSA-related infection distribution by hospital wards.

Out of 1987 staphylococci-infected isolates collected between 2008 and 2012, 542 (27.4\%) were MRSA-related infections and $1445(72.6 \%)$ were S. aureus-related infections. The annual rate of MRSA-related infections in our hospital showed a slight downward trend, from $32.6 \%$ in 2008 to $25.5 \%$ in $2012\left(\chi^{2}=12.41, \mathrm{p}=0.0145\right)$. Table 1 shows that the MRSA-related infections showed an increase compared to $S$. aureusrelated infections in wound and aspirate samples in 2011 and 2012 (57.9\%/34.9\% and $35.2 \% / 16.3 \%$, respectively).

Figure 1 shows that isolates from the surgical wardd and ICU had higher rates of MRSA-related infection $(49.8 \%$ and $27.9 \%$, respectively) than samples from the internal medicine, infectious and paediatric units $(12.7 \%, 6.8 \%$, and $2.8 \%$, respectively). This difference was statistically significant $\left(\chi^{2}=113.46, \mathrm{p}<0.0001\right)$. 


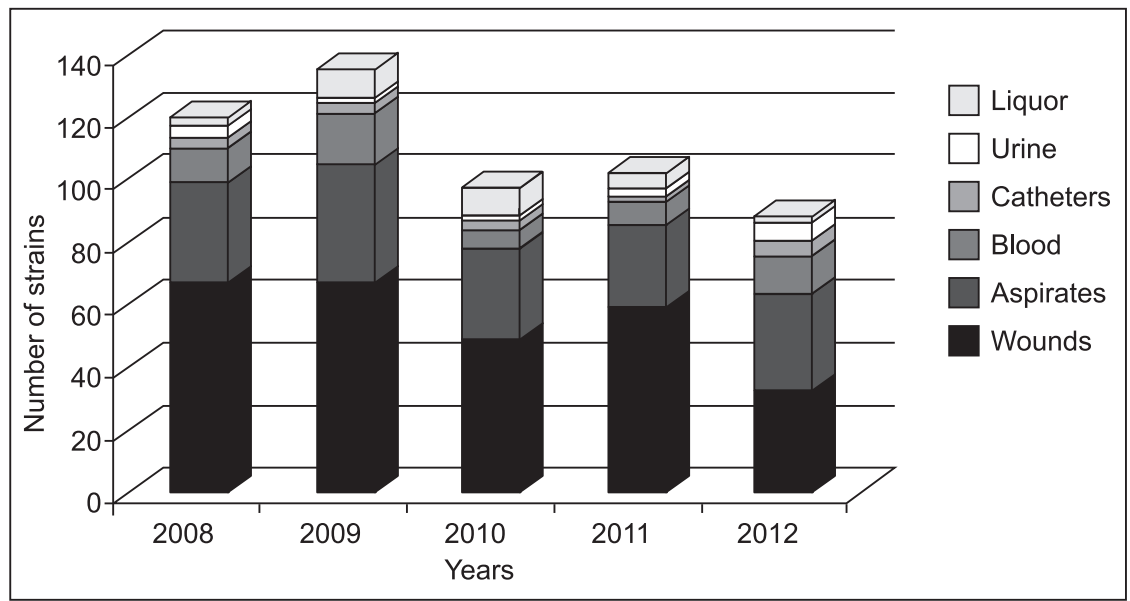

Figure 2 MRSA-related infection distribution by clinical samples.

Table 2 Antibiotic susceptibility of MRSA-related infection isolates

\begin{tabular}{llllll}
\hline \multirow{2}{*}{$\begin{array}{l}\text { Antimicrobial } \\
\text { agent }\end{array}$} & $\begin{array}{l}\text { Number of susceptible MRSA-infection } \\
\text { 2008 } \\
\text { (n=120) }\end{array}$ & $\begin{array}{l}2009 \\
(\mathrm{n}=135)\end{array}$ & $\begin{array}{l}2010 \\
(\mathrm{n}=97)\end{array}$ & $\begin{array}{l}2011 \\
(\mathrm{n}=102)\end{array}$ & $\begin{array}{l}2012 \\
(\mathrm{n}=88)\end{array}$ \\
\cline { 2 - 6 } & $\mathrm{n}(\%)$ & $\mathrm{n}(\%)$ & $\mathrm{n}(\%)$ & $\mathrm{n}(\%)$ & $\mathrm{n}(\%)$ \\
\hline Ciprofloxacin & $2(1.7)$ & $10(7.4)$ & $6(6.2)$ & $6(5.9)$ & $5(5.7)$ \\
Gentamycin & $9(7.5)$ & $11(8.1)$ & $7(7.7)$ & $17(16.6)$ & $11(12.5)$ \\
Clindamycin & $3(2.5)$ & $9(6.6)$ & $2(2.1)$ & $7(6.7)$ & $1(1.1)$ \\
Erythromycin & $3(2.5)$ & $3(2.2)$ & $1(1)$ & $8(7.8)$ & $4(4.5)$ \\
Netilmycin & $119(99.2)$ & $133(98.5)$ & $94(96.9)$ & $91(89.2)$ & $66(75)$ \\
Linezolid & $120(100)$ & $135(100)$ & $97(100)$ & $102(100)$ & $88(100)$ \\
Rifampicin & $115(95.8)$ & $116(85.9)$ & $67(69.1)$ & $90(88.2)$ & $80(90.9)$ \\
Teicoplanin & $120(100)$ & $135(100)$ & $97(100)$ & $102(100)$ & $88(100)$ \\
Vancomycin & $120(100)$ & $135(100)$ & $97(100)$ & $102(100)$ & $88(100)$ \\
Sulfamethoxazole & $92(76.6)$ & $115(85.2)$ & $75(77.3)$ & $81(79.4)$ & $72(81.8)$ \\
trimethoprim & & & & &
\end{tabular}

Out of 542 MRSA-related infections samples analysed in this 5 year study, the majority was detected in wound swabs $(50.6 \%)$ and aspirates (28.8\%) (Figure 2).

A significantly lower level of MRSA-related infections was detected in blood (10.0\%), urine $(2.9 \%)$, catheters $(2.6 \%)$, and liquor $(5.1 \%)$ samples $\left(\chi^{2}=128.11, \mathrm{p}<0.0001\right)$.

Table 2 summarizes the susceptibility of 542 MRSA-related infection isolates to several antimicrobial drugs used in the treatment of MRSA infections. All MRSA-related infection strains analysed in this study were susceptible to vancomycin, teicoplanin and linezolid.

In contrast, less than $10 \%$ of MRSArelated infection strains were susceptible to erythromycin or clindamycin. Their highest susceptibility to these two antibiotics was detected in 2011 (7.8\% and 6.7\%, respectively). While the susceptibility of MRSA-related infection strains to netilmycin showed a downward trend, their susceptibility to ciprofloxacin and gentamycin increased (from 1.7\% and $7.5 \%$ in 2008 to $5.7 \%$ and $12.5 \%$ in 2012). 


\section{Discussion}

The overall frequency of MRSA-related infections between 2008 and 2012 at Osijek Clinical Hospital was $27.4 \%$. This rate correlated with the results reported by Mehta et al. (32.0\%) but was smaller than those reported by Kuehnert et al., Anupurba et al. and Tiwari et al. (43.2\%, 54.8\% and 69.1\%, respectively) (14, 20-22). MRSA-related infection from blood and liquor samples in 2010 and 2011 was $14.5 \%$ and $12.8 \%$ which is similar to the results reported from Croatia by Budimir et al. and from the United States of America by Hacek et al. $(23,24)$. The slight downward trend in the annual frequency of MRSA-related infections at Osijek Clinical Hospital may be explained by the rising awareness of MRSA, more efficient prevention programs and less frequent antibiotic administration.

With a capacity of 1160 beds, Osijek Clinical Hospital is the largest healthcare centre in north-east Croatia. The largest incidence of MRSA-related infections was detected in the surgical ward and the ICU. The latter is a polyvalent unit with 12 beds and $3 / 4$ of its patients arrive from surgical units. This rate correlated with the results reported by Joshi et al. (25).

The largest number of MRSA-related infections was detected in wound swabs and aspirates. The high incidence of MRSA-related infections in aspirates is linked to the fact that ICU patients underwent endotracheal intubation. These results correlated with reports from Pakistan and India $(4,21)$. All MRSA strains detected in this study were susceptible to vancomycin, linezolid and teicoplanin. Vancomycin-sensitive MRSA strains were also reported in studies from Bosnia and Herzegovina, Romania, Ireland, the United Kingdom, India, and Columbia (23, 26-31). However, vancomycin-resistant S. aureus (VRSA) strains were discovered in the USA $(32,33)$.
The majority of our MRSA strains were not susceptible to erythromycin and clindamycin. Moreover, their susceptibility to netilmicin showed a downward trend between 2008 and 2012. On the other hand, their susceptibility to ciprofloxacin and gentamycin increased during this 5 -year period. These observations correlate with the results reported by the Committee for Antibiotic Resistance Surveillance in Croatia (Croatian Academy of Medical Sciences).

\section{Conclusion}

In conclusion, despite some limitations (the lack of epidemiological evidence about the reason and length of hospital stay), this 5-year study was the first study on MRSArelated infection frequency and antibiotic resistance in hospital patients from northeast Croatia. This study demonstrates that MRSA-related infection is a problem in north-east Croatia. Due to the $100 \%$-efficient susceptibility of MRSA strains in patients at the Osijek Clinical Hospital to vancomycin, linezolid and teicoplanin, these antibiotics should be avoided in therapy. Further monitoring is necessary of the use of antibiotics, incidence of MRSA-related infections and their antibiotic susceptibility. This study can enable epidemiologists to understand the nature of MRSA infections in north-east Croatia.

\section{What is already known on this topic}

- MRSA is one of the most common causes of healthcareassociated infections. The most important MRSA related problem is the development of resistance to antibiotics.

\section{What this study adds}

- This study shows that regular surveillance of hospitalassociated infections and monitoring of their antibiotic sensitivity patterns are required to reduce MRSA-infection frequency in hospital patients from north-east Croatia. Accurate and continuous surveillance of antibiotic resistance combined with the more rational use of antibiotics are crucial for reducing MRSA-related infections. 
Acknowledgments: The authors would like to thank all participants in our study. The authors also greatly appreciate the help received from Dr Marcela Čović for data analysis and article revision. Also, we would like to thank the Institute of Public Health of the Osijek-Baranja County for it support.

Autors' contributions: Conception and design: TP, MP, DV; Acquisition, analysis and interpretation of data: NR, VA; Drafting the article: ZB, JT; Revising it critically for important intellectual content: PRM, LZS.

Conflict of interest: The authors declare that they have no conflict of interest.

\section{References}

1. Kalenić S. The importance of methicillin-resistant Staphylococcus aureus in human medicine. Medical Sciences. 2012;37:61-71.

2. Que YA, Moreillon P. Staphylococcus aureus (including staphylococcal toxic shock). In: Mandell GL, Bennett JE, Dolin R, editors. Principles and Practice of infectious diseases. 7th ed. Philadelphia: Churchill Livingstone Elsevier; 2010. p. 2543-78.

3. Gordon RJ, Lowy FD. Pathogenesis of MethicillinResistant Staphylococcus aureus Infection. Clin Infect Dis. 2008;46(5):S350-9.

4. Mahmood K, Tahir T, Jameel T, Ziauddin A, Aslam HF. Incidence of methicillin resistant Staphylococcus aureus (MRSA) causing nosocomial infection in a tertiary care hospital. Annals KEMU. 2010;16:91-6.

5. Milas J, Kalenić S, Milas V, Miškulin M, Vuković D, Rudan S, et al. Effect of Aminglycoside Administration on the Occurrence and Multiplication of Resistant Bacteria. Coll. Antropol. 2009;33(2):57985.

6. Köck R, Becker K, Cookson B, van Gemert-Pijnen JE, Harbarth S, Kluytmans J, et al. Methicillinresistant Staphylococcus aureus (MRSA): burden of disease and control challenges in Europe. Euro Surveill. 2010;15(41):pii=19688.

7. Ray P, Gautam V, Singh R. Methicillin-resistant Staphylococcus aureus (MRSA) in developing and developed countries: implications and solutions. Regional Health Forum. 2011;15(1):74-82.

8. Klein E, Smith DL, Laxminarayan R. Hospitalizations and Deaths Caused by Methicillin-Resistant Staphylococcus aureus, United States, 199-2005. Emerg Infect Dis. 2007;13(2):1840-6.
9. Köck R, Schaumburg F, Mellmann A, Köksal M, Jurke A, Becker K, ea al. Livestock-Associated Methicillin-Resistant Staphylococcus sureus (MRSA) as Causes of Human Infection and Colonization in Germany. PLoS One. 2013;8(2):e55040.

10. Hetem DJ, Bootsma MCJ, Troelstra A, Bonten MJM. Transmissibility of Livestock-associated Methicilin-Resistant Staphylococcus aureus. Emerg Infect Dis. 2013;19(11):1797-802.

11. Warshawsky B, Hussain Z, Gregson DB, Alder R, Austin M, Bruckschwaiger D, et al. Hospital- and Community-Based Surveillance of MethicillinResistant Staphylococcus aureus: Previous Hospitalization is the Major Risk Factor. Infect Control Hosp Epidemiol. 2000;21(11):724-7.

12. Eames I, Tang JW, Li Y, Wilson P. Airborne transmission of disease in hospitals. J. R. Soc Interface. 2009;6:697-702.

13. Mihaljević LJ, Bedenić B, Mihaljević S, Majerović M, Petrović P, Vasilj I. Microbiological Surveillance of the Surgical Intensive Care Unit in Zagreb - A Pivot for Guideline-Based Therapy of Severe Sepsis. Coll Antropol. 2007;31(4):1093-7.

14. Anupurba S, Sen MR, Nath G, Sharma BM, Gulati AK, Mohapatra TM. Prevalence of methicillin resistant Staphylococcus aureus in a tertiary referral hospital in eastern Uttar Pradesh. Indian J Med Microbiol. 2003;21(1):49-51.

15. Kalenić S, Pal MP, Palčevski VV, Horvatić J, Meštrović $\mathrm{T}$, Baršić $\mathrm{B}$, et al. Guidelines for prevention, control and treatment of infections caused by methicillin-resistant Staphylococcus aureus (MRSA). Liječ Vjesn. 2010;132:340-4.

16. Budimir A. Detection and typing methods of methicillin-resistant Staphylococcus aureus strains. Medical Sciences. 2012;37:73-88.

17. Pujate E, Balode A, Oss P, Dumpis U. Association between antibiotic use and incidence of methicillin-resistant Staphylococcus aureus in general intensive care. ESCMID [Internet]. 2007 [cited 2013 Feb 20]. Available from: http://www.blackwellpublishing.com/eccmid17/abstract.asp?id=57889.

18. Leclercq R, Cantón R, Brown DF, Giske CG, Heisiq $P$, MacGowan AP, et al. EUCAST expert rules in antimicrobial susceptibility testing. Clin Microbiol Infect. 2013;19:141-60.

19. Tambić A. Methicillin-resistant Staphylococcus aureus (MRSA), a predictor of the end of the antibiotic era-diagnosis, epidemiology, therapy and dissemination prevention [on Croatian]. Liječ Vjesn. 1997;119:166-71.

20. Kuehnert MJ, Hill HA, Kupronis BA, Tokars JI, Solomon SL, Jernigan DB. Methicillin-resistant- 
Staphylococcus aureus Hospitalizations, United States. Emerg Infect Dis. 2005;11(6):868-72.

21. Mehta AA, Rodrigues CC, Kumar RR, Rattan A, Sridhar H, Mattoo V, et al. A pilot programme of MRSA surveillance in India. (MRSA Surveillance Study Group). JPGM. 1996;42(1):1-3.

22. Tiwari HK, Das AK, Sapkota D, Sivrajan K, Pahwa VK. Methicillin resistant Staphylococcus aureus: Prevalence and antibiogram in a tertiary care hospital in western Nepal. J Infect Dev Ctries. 2009;3(9):681-4.

23. Budimir A, Bošnjak Z, Kalenić S. Methicillin-resistant Staphylococcus aureus (MRSA) in Croatia. Infektološki Glasnik. 2012;32(2):59-66.

24. Hacek DM, Paule SM, Thomson RB, Robicsek A, Peterson LR. Implementation of a Universal Admission Surveillance and Decolonization Program for Methicilin-Resistant Staphylococcus aureus (MRSA) Reduces the Number of MRSA and Total Number of S. aureus Isolates Reported by the Clinical Laboratory. J Clin Microbiol. 2009;47(11):3749-52.

25. Joshi S, Ray P, Manchanda V, Bajaj J, Chitnis DS, Gautam V. Methicillin resistant Staphylococcus aureus (MRSA) in India: Prevalence \& susceptibility pattern. Indian J Med Res. 2013;137(2):3639.

26. Nickerson EK, West TE, Day NP, Peacock SJ. Staphylococcus aureus disease and drug resistance in resource-limited countries in south and east Asia. Lancet Infect Dis. 2009;9(2):130-5.
27. Butt T, Ahmad RN, Usman M, Mahmood A. Methicillin-resistant Staphylococcus aureus, Pakistan, 1996-2003. Emerg Infect Dis. 2004;10(9):1691-2.

28. Contreras G, Prieto R, Leal A. Antimicrobial susceptibility of the pathogens of bacteraemia in a tertiary neonatal intensive care unit in Bogota, Colombia, 2001-2006. ECCMID [Internet]. 2007 [cited 2013 Feb 19]. Available from: http://www. blackwellpublishing.com/eccmid17/abstract. asp?id=57332.

29. Šišrak M, Zvizdić A, Hukić M. Methicillin-Resistant Staphylococcus Aureus (MRSA) as a Cause of Nosocomial Wound Infections. Bosn J Basic Med Sci. 2010;10(1):32-7.

30. Tambić Andrašević A, Tambić T, KatalinićJanković V, Payerl Pal M, Bukovski S, Butić I, et al. Antibiotic resistance in Croatia. Zagreb: The Croatian Academy of Medical Sciences; 2012.

31. Dragomirescu CC, Codita I, Oprea M. Antimicrobial resistance of $\mathrm{S}$. aureus strains isolated in 2005 from nosocomial infections in Romania. ESCMID [Internet]. 2007 [cited 2013 Feb 20]. Available fom: http://www.blackwellpublishing.com/ eccmid17/abstract.asp?id=57620.

32. Chang S, Sievert DM, Hageman JC, Boulton ML, Tenover FC, Downes FP, et al. Infection with Vancomycin-Resistant Staphylococcus aureus Containing the vanA Resistance Gene. N Engl J Med. 2003;348:1342-7.

33. Whitener CJ, Park SY, Browne FA, Parent LJ, Julian K, Bozdogan B, et al. Vancomycin-resistant Staphylococcus aureus in the absence of vancomycin exposure. Clin Infect Dis. 2004;38:1049-55. 